Review

\title{
Investigation of Interfacial Bonding and Thermal Stability for the Hybrid NCF Composites added with (3-Aminopropyl) trimethoxysilane-modified $\mathrm{SiO}_{2}$ nanoparticles
}

\author{
Yun $\mathrm{Oh}^{1,2}$, Jeong Seok Kang, ${ }^{1,2}$, Min-Kang $\mathrm{Seo}^{2}$, Min Sang Lee ${ }^{3}$, Lee Ku Kwac ${ }^{3}$, Jeong Ho \\ Kwac ${ }^{4}$ Jong Bae Park, and Gyo Woo Lee ${ }^{*}$ \\ ${ }^{1}$ Division of Mechanical Design Engineering, Jeonbuk National University, Jeonju 54896, Republic of \\ Korea; mismaryurica@naver.com (Y.O.); kjs@kctech.re.kr (J.S.K.) \\ ${ }^{2}$ Korea Institute of Carbon Convergence Technology, Jeonju 54853, Republic of Korea; \\ seomk721@kctech.re.kr (M.K.S.) \\ ${ }^{3}$ Mechanical and Automotive Engineering, Jeonju University, Jeonju 55069, Republic of Korea; lovely- \\ lms@hanmail.net (M.S.L.); kwac29@jj.ac.kr (L.K.K.) \\ ${ }^{4}$ Metallurgical Engineering, Jeonbuk National University, Jeonju 54896, Republic of Korea; \\ kwakjh@jbnu.ac.kr (J.H.K.) \\ ${ }^{5}$ Korea Basic Science Institute Center, Jeonju 54907, Republic of Korea; jbpjb@kbsi.re.kr (J.B.P.)
}

\footnotetext{
* Correspondence: e-mail: gwlee@jbnu.ac.kr; Tel:+82-63-270-3997; Fax: +82-63-270-2460)
} 


\begin{abstract}
To expand the application scope and increase the demand for non-crimp fabrics (NCFs) as a lightweight vehicle material, the delamination and thermal strain in NCF composites must be restricted. Accordingly, to simultaneously improve the interfacial bonding and thermal stability of the NCF composites, in this study the epoxy resin, in which $\mathrm{SiO}_{2}$ nanoparticles was modified by a silane coupling agent, were infused to the stacked NCFs and between the layers of NCFs through the vacuum-assisted resin infusion molding (VARIM) process.

The mechanical properties improved when the NCF composites were added with either unmodified or surface-modified $\mathrm{SiO}_{2}$ nanoparticles. In particular, the hybrid composite added with $0.6 \mathrm{wt} \%$ modified $\mathrm{SiO}_{2}$ nanoparticles showed higher increase in the interlaminar shear strength (ILSS), tensile strength, and impact strength of approximately $26.6 \%, 26.7 \%$, and 24.7 $\%$, respectively, relative to those of the NCF composites. Also, the surface-modified $\mathrm{SiO}_{2}$ nanoparticles reduced the thermal strain of the NCF composites and improving its thermal stability.
\end{abstract}

Keywords: Non-crimp fabrics; Epoxy composites reinforced with NCFs; Silane coupling agent; Surface-modified $\mathrm{SiO}_{2}$ nanoparticles; Mechanical properties; Interfacial bonding; Thermal stability 


\section{Introduction}

As environmental issues and climate change measures are drawing increasing attention, the automotive industry is betting life and death on lightweight vehicles as a way to improve fuel efficiency and reduce vehicular emissions. Reducing the vehicle weight by $10 \%$ generally increases the fuel efficiency by $4-8 \%$ [1]. Moreover, automotive manufacturers must satisfy the fuel efficiency regulations in a specific country to sell their vehicles in its markets. Therefore, the production of lightweight vehicles has become a key strategic goal. Methods for producing lightweight vehicles include reducing material use by improving the material structure or production method. However, the most effective method is to replace the heavy and usually metal-based parts with lighter alternatives. Consequently, the automotive manufacturing industry is focusing on carbon fiber reinforced polymer composites (CFRP) as a core material for lightweight vehicles.

Carbon fibers (CFs), which is the reinforcement for CFRP, has excellent tensile strength, modulus of elasticity, and conductivity, and they can be used to prepare fabrics. These CFs-based fabrics are largely classified into woven and NCFs depending on how they are fabricated. In woven fabrics, crimps are generated on the partial dip due to the interlacing of cross-linked fiber bundles. For NCFs, fibers are oriented in the longitudinal (warp, $0^{\circ}$ ), transverse (weft, $90^{\circ}$ ), or diagonal (bias, $30^{\circ}<\theta<90^{\circ}$ ) directions, and then through the stitching process, are fixed in the thickness direction, without crimps being generated in the fiber $[2,3]$.

Woven fabrics have poor in-plane mechanical properties, owing to the wavy crimps caused by the structural characteristics of weaving; therefore, NCFs are increasingly used to avoid this problem [4-7].

NCFs are capable of fiber orientation in multi-axial directions within a single fabric, and multiple fibers with various angles are composed into one layer, so that the fiber characteristics of each layer can be maintained. Since fibers in each layer can be arranged in a straight line, in such the NCFs, it is suitable for use in resin transfer molding and vacuum assisted resin infusion molding (VARIM), which allow the fiber to be impregnated more uniformly into the resin [5, 79]. In addition, when composites are manufactured using NCFs, cost reduction and process simplification can be achieved, which has led to NCFs being used in a variety of high performance applications, such as to the bodies of BMW i3 cars, the rear pressure bulkheads of Airbus A380 airplanes, and to wind turbine wings over $60 \mathrm{~m}$ long [10].

CFRP is replacing various metallic materials for vehicle parts, owing to their excellent strength, fatigue properties, durability, and corrosion resistance. However, CFRP is more expensive than other lightweight materials and can undergo delamination by external impact because of the weak physical bond between the CFs and resin [11, 12]. Furthermore, although the surrounding environment rarely affects the $\mathrm{CFs}$, the resin is sensitive to temperature, humidity, and ultraviolet light $[13,14]$. Therefore, these environmental conditions can mechanically degrade CFRP and reduce their durability $[15,16]$.

CFRP-based materials for automotive applications must also be free of deformations caused by high temperatures. When a vehicle is parked outside, the temperature of its components can increase to $70{ }^{\circ} \mathrm{C}$ or higher due to the recent temperature rises caused by global warming and summer heatwaves. Therefore, the CFRP-based structural and interior/exterior materials for vehicles must withstand thermal strain at high temperatures and ultraviolet light exposure. Also, the parts that constitute an automotive engine and its surroundings require excellent heat resistance and strength to endure the heat generated by the vehicle motor and transmitted through the hood.

To restrict delamination at the CFs and resin interface, which is a disadvantage of CFRP, their interfacial bonding strength has been enhanced by processing the CFs surface via oxidation, 
sizing, plasma, and silane coupling agents, as well as a hybrid method that adds nanoparticles and short fibers to the resin [17-21]. For example, Khan et al. [22] fabricated hybrid CFRP by mixing graphitic nanoplatelets modified with nitrogen and a silane coupling agent into an epoxy resin. This composite exhibited $\sim 27.4 \%$ increase in the ILSS relative to that of pristine CFRP without the nanoplatelets.

Silica $\left(\mathrm{SiO}_{2}\right)$ particles are widely used as filler for cosmetic materials, paper, tires, and paints, owing to their excellent mechanical strength, adsorption, and heat resistance. Numerous previous studies have reported the improvement in the mechanical and thermal properties of polymer composites by adding $\mathrm{SiO}_{2}$ particles [23-25]. In one such study, Oh et al. [26] added $\mathrm{SiO}_{2}$ particles with a low coefficient of thermal expansion (CTE) to epoxy composites, which reduced the thermal strain on the composites caused by the difference in the CTEs of the filler and resin, thus improving the mechanical properties and thermal stability of the composites.

However, numerous hydrophilic silanol groups $(\mathrm{Si}-\mathrm{OH})$ exist on the surface of $\mathrm{SiO}_{2}$ particles, which can cause particles to agglomerate and reduce their compatibility with hydrophobic resins, thereby decreasing their dispersibility [27]. This problem can be solved by making the $\mathrm{SiO}_{2}$ particles less hydrophilic using a silane coupling agent or by functionalizing the $\mathrm{SiO}_{2}$ particles with groups that improve the compatibility and bonding strength between the $\mathrm{SiO}_{2}$ particles and resins [28-30].

Silane coupling agent molecules have two types of functional groups with different reactivities, and they enable reactions between inorganic filler and organic polymer chains through hydrolysis. The alkoxyl groups (methoxy and ethoxy groups) in such molecules become silanol groups through hydrolysis, which then form hydrogen or siloxane bonds with the hydroxyl groups $(-\mathrm{OH})$ or other silanol groups that exist on the $\mathrm{SiO}_{2}$ surface. Other organic functional groups (vinyl, epoxy, and amino groups) can also interact with the resin and enhance its affinity toward the $\mathrm{SiO}_{2}$ particles. After hydrolysis, chemical bonds are formed between the filler and resin, which ultimately increase the mechanical strength of the composite [31]. The silane coupling agent here is credited to play the role of improving the filler's compatibility with the resin as well as its dispersibility [32].

Wei et al. [33] improved the mechanical properties of composites by coating the surface of basalt fibers with an epoxy resin and $\mathrm{SiO}_{2}$ nanoparticles modified with a silane coupling agent, thereby improving the interfacial bond between the filler and resin. Consequently, the tensile strength and ILSS of the modified composites increased by approximately $30 \%$ and $15 \%$, respectively, relative to those of the unmodified basalt fiber reinforced polymer composites. Furthermore, Yang et al. [34] increased the ILSS of the CFRP by approximately $14 \%$ by mixing $\mathrm{SiO}_{2}$ nanoparticles modified with a silane coupling agent into the epoxy resin.

Like other woven fabrics, NCFs also faces the problem of delamination and thermal strain during CFRP production. Existing studies on NCF composites have focused on the variations in its mechanical properties according to the fiber lamination angle and the stitch shape and direction; most of the research was related to this subject. To expand the application scope and increase the demand for NCFs as a lightweight vehicle material, the delamination and thermal strain in NCF composites must be restricted.

Therefore, this study aims to increase the interfacial bonding strength and thermal stability of NCF composites. The epoxy resin, in which $\mathrm{SiO}_{2}$ nanoparticles were modified by a silane coupling agent, was infused to the stacked NCFs and between the layers of NCFs through the VARIM process. In addition, the epoxy composites reinforced with NCFs added with either $\mathrm{SiO}_{2}$ nanoparticles or $\mathrm{SiO}_{2}$ nanoparticles modified with a silane coupling agent were analyzed by ILSS, tensile strength, impact strength, and CTE tests. The mechanical and thermal properties of these composites were compared according to the $\mathrm{SiO}_{2}$ nanoparticle type. 


\section{Materials and Methods}

\subsection{Meterial}

The viscosity of the epoxy resin (KINETIX R118, ATL composites) used for composites fabrication was $450 \mathrm{mPa}$, and the mixing weight ratio of the epoxy resin and hardener (KINETIX H120, ATL composites) was 4:1.

$\mathrm{SiO}_{2}$ nanoparticles (fumed silica, S5130, SIGMA-ALDRICH) were selected as the additive considering their strength and heat resistance, impregnability, and formability, and formation of a smooth and stable dispersion of the filler in the resin.

APTMS, a representative silane coupling agent, was selected to avoid the agglomeration of the $\mathrm{SiO}_{2}$ nanoparticles and to increase their compatibility and interfacial bonding strength with the epoxy resin. When the wet method is used to modify the $\mathrm{SiO}_{2}$ nanoparticles using (3aminopropyl) trimethoxysilane (APTMS, SIGMA-ALDRICH), the loss rate in the refining process is high and the treatment process is complex. Therefore, in this study, $\mathrm{SiO}_{2}$ nanoparticles were added to a shear mixing container, $0.8 \mathrm{wt} \%$ APTMS was applied to the particles using a pipette, and the resin was then mixed in after physical agitation (integral blend method). The reaction mechanism of $\mathrm{SiO}_{2}$ nanoparticles and APTMS is shown in Fig. 1.

Meanwhile, to measure the contact angle by the wicking method, colloidal silica was produced by mixing deionized water and $\mathrm{SiO}_{2}$ nanoparticles at a weight ratio of 1:1. Subsequently, $30 \mathrm{~g}$ of APTMS was added to $30 \mathrm{~g}$ of colloidal silica, and the mixture was stirred for $2 \mathrm{~h}$. NCFs were then immersed separately in the same amount of colloid silica for $24 \mathrm{~h}$ and in the colloidal silica wherein APTMS was dispersed. Following this, they were fully dried in an oven at $80^{\circ} \mathrm{C}$. Various properties of the epoxy composite, NCFs and or $\mathrm{SiO}_{2}$ nanoparticles, which were available through technical data sheets provided by the manufacturer and from published literature, have been listed in Table 1. The shape of the biaxial NCFs with fiber oriented at $0^{\circ} /$ $90^{\circ}$, the epoxy composites reinforced with NCFs, and the tricot weaving method are shown in Table 2. 


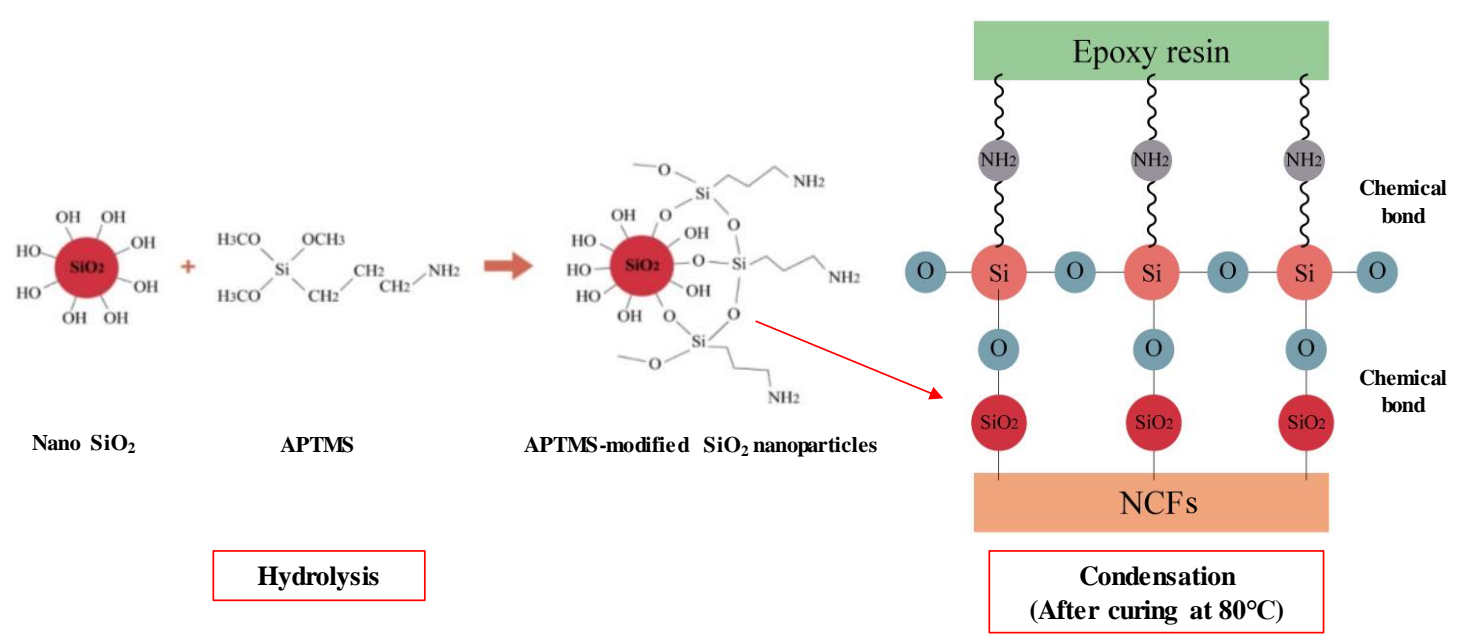

Figure 1. The idealized mechanism of APTMS surface grafted $\mathrm{SiO}_{2}$ nanoparticles.

Table 1. Properties of epoxy composites, NCFs and $\mathrm{SiO}_{2}$ nanoparticles used in this study.

\begin{tabular}{|c|c|c|c|}
\hline & $\begin{array}{c}\text { Epoxy } \\
\text { Composites } \\
\text { (Matrix) }\end{array}$ & $\begin{array}{c}\text { NCFs } \\
\text { (Reinforcement) }\end{array}$ & $\begin{array}{c}\mathrm{SiO}_{2} \\
\text { (Additive) }\end{array}$ \\
\hline $\begin{array}{c}\text { Tensile Strength } \\
\text { (MPa) }\end{array}$ & 71 & 4,137 & 155 \\
\hline $\begin{array}{l}\text { Young's modulus } \\
\text { (GPa) }\end{array}$ & 3.08 & 242 & $70-78$ \\
\hline $\begin{array}{c}\text { Coefficient of } \\
\text { Thermal Expansion } \\
\left(10^{-6} / \mathbf{K}\right)\end{array}$ & 43.92 & $0.83-6.84$ & $0.4-2.43$ \\
\hline $\begin{array}{c}\text { Density } \\
\text { (g/cc) }\end{array}$ & 1.08 & 1.81 & $2.20-2.65$ \\
\hline
\end{tabular}

* http://www.mattweb.com, zoltek.com, azom.com, and atlcomposites.com.au 
Table 2. The shape of the biaxial NCFs with fiber oriented at $0 / 90^{\circ}$, the NCF composites, and the tricot weaving method.

\section{Biaxial NCFs NCF composites}

Front Shape

Back Shape
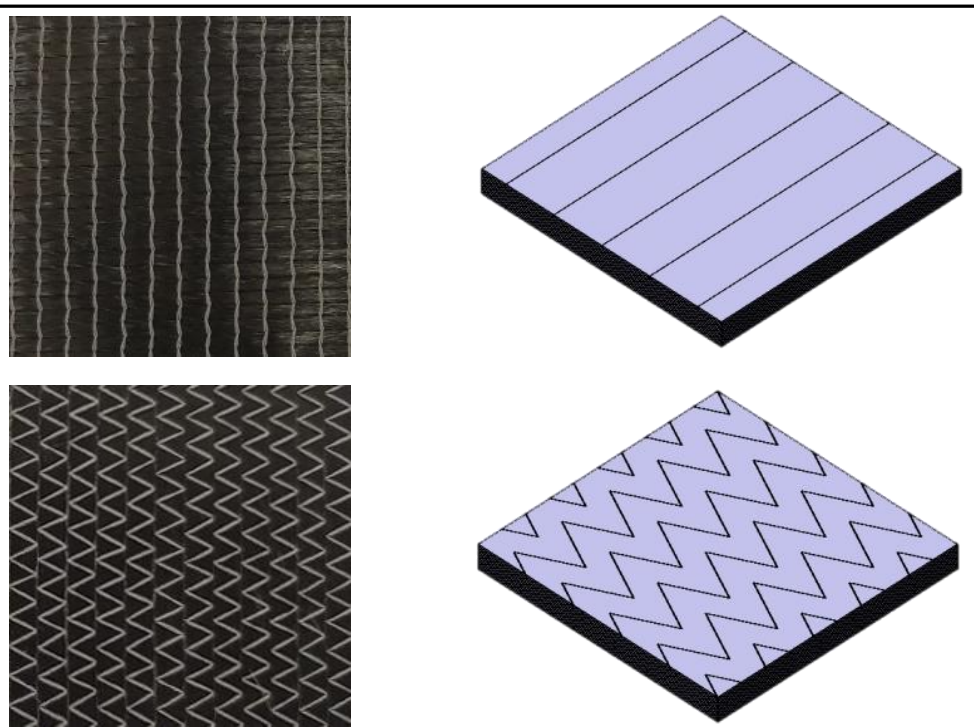

\subsection{Fabrication of epoxy composites reinforced with NCFs and added with $\mathrm{SiO}_{2}$ nanoparticles using the VARIM process}

The VARIM process consists of filling a low viscosity liquid resin into a material using the difference between the external atmospheric pressure and the internal pressure of a vacuum bag, i.e., the pressure gradient between the resin inlet and outlet causes the resin to flow. In this study, the $\mathrm{SiO}_{2}$ nanoparticles and the $\mathrm{SiO}_{2}$ nanoparticles modified with the silane coupling agent were uniformly dispersed in the resin using the shear force generated by high speed rotation.

To fabricate an epoxy resin and $\mathrm{SiO}_{2}$ particles mixture, $0.2 \mathrm{~g}$ of defoamer BYK-A 500 (BYKChemie Co. Ltd) was added to $160 \mathrm{~g}$ of resin to remove air bubbles contained in the resin itself, and then $\sim 0.6 \mathrm{wt} \%$ of $\mathrm{SiO}_{2}$ and surface modified $\mathrm{SiO}_{2}$ nanoparticles was added. The mixture was mixed with a shear mixer (PDM-300 Paste mixer, Daewha Tech Co. Ltd) at rotation speeds of 1,000 and 1,100 rpm, respectively, for $20 \mathrm{~min}$. Then, $40 \mathrm{~g}$ of hardener was added to the mixture, which was supplementary shear mixed for $2 \mathrm{~min}$.

In order to fabricate NCF composites by the VARIM process, a sufficient amount of mold release agent (FLEX-Z 6.0, Chem Trend Release Innovation) was applied to a tempered glass surface, and then a $500 \times 600 \mathrm{~mm}$ space was sealed off, using sealant tape. A tee connector and spiral hose were used in the resin inlet and outlet, to create the space needed to apply infusion, discharge, and vacuum pressure to the resin. A breather line was also added, in front of the vacuum line, to prevent resin overflow, and was connected to a vacuum reservoir so as to prevent residual resin from entering the vacuum pump (W2V20, WSA Co. Ltd). The vacuum was applied after performing sealing and vacuum bag work using a sealant tape and a vacuum film. The 
mixture was then infused into the stacked NCFs under 1 bar of vacuum pressure through the resin inlet.

However, impregnation did not progress properly owing to the increased viscosity of the resin in the mixtures with more than $0.7 \mathrm{wt} \% \mathrm{SiO}_{2}$ nanoparticles. Thus, these composites were excluded from further analysis. For the FE-SEM characterization, tensile strength, and CTE tests, five ply NCFs were used, while for the ILSS and impact tests, six and eight ply NCFs were used.

\subsection{Specimen processing and Property measurement}

The NCF composites are managing into $280 \times 280 \mathrm{~mm}$ sections, using a waterjet, the specimens were further processed using cutting, routing, and drilling (CRD) equipment, to reduce physical property variations which may have been caused by molding or processing defects. Final the tensile strength specimens were $250.0 \mathrm{~mm}$ length, $4.8 \mathrm{~mm}$ width and $2.4 \mathrm{~mm}$ thickness, the ILSS specimens were $14.4 \mathrm{~mm}$ length, $4.8 \mathrm{~mm}$ width and $2.4 \mathrm{~mm}$ thickness, the impact strength specimens were $63.5 \mathrm{~mm}$ length, $12.7 \mathrm{~mm}$ width and $3.2 \mathrm{~mm}$ thickness, while the CTE specimens were $25 \mathrm{~mm}$ length, $5.0 \mathrm{~mm}$ width, and $2.0 \mathrm{~mm}$ thickness.

To understand the morphology of the epoxy composites reinforced with NCFs and added with $\mathrm{SiO}_{2}$ nanoparticles (hybrid NCF composites), the fracture surfaces of the specimens were observed under a scanning electron microscope. The FE-SEM specimens were pre-coated with platinum, and images of the microstructure of the fracture surfaces were captured under an acceleration voltage of $3.0 \mathrm{kV}$.

To examine the surface free energy of NCFs according to the APTMS-modified $\mathrm{SiO}_{2}$ nanoparticles, the contact angle was measured using a surface tension meter (K-100, Krüss). An analysis of the surface free energy is evaluated in terms of the surface energetic studies, which is divided by two components: London dispersive components of nonpolar interaction and specific (or polar) components describing all types of interactions (Debye, Keesom, hydrogen bonding, $\pi$-bonding and other small polar effects). The London dispersive and specific components of surface free energy of CFs were determined by measuring the contact angles of a variety of testing liquids with known London dispersive and specific components and analyzing the results in accordance with the method proposed by Owens and Wendt [35] and Kaelble [36], using the geometric mean, as follows:

$$
\frac{\gamma_{L}(1+\cos \theta)}{2\left(\gamma_{L}^{L}\right)^{1 / 2}}=\left(\gamma_{S}^{S P}\right)^{1 / 2} \cdot\left(\frac{\gamma_{L}^{S P}}{\gamma_{L}^{L}}\right)^{1 / 2}+\left(\gamma_{S}^{L}\right)^{1 / 2}
$$

where the subscripts $L$ and $S$ represent the liquid and solid states, respectively. And, $\gamma^{L}$ and $\gamma^{S P}$ are the London dispersive (superscript L) and specific (superscript SP) components of the surface free energy of the constitutive elements. The surface free energies for the wetting liquids and their London dispersive and specific components are listed in Table 3.

To examine the mechanical properties of the fabricated hybrid NCF composites, their tensile strength and ILSS were measured using a universal testing machine, while a plastic impact tester determined their impact strength. The tensile strength test was performed in accordance with ASTM D3039, and the crosshead speed of $2 \mathrm{~mm} / \mathrm{min}$ was used to create a semi-equilibrium state. 
The ILSS was measured with a universal testing machine, in accordance with ASTM D2344. Both ends of the specimens were supported using pins with $3 R$ radii, the test span was $4 \times$ the thickness of the specimens, and the strength at which fracture occurred at the interface was measured by applying a load to the center of the specimens, at a load speed of $1 \mathrm{~mm} / \mathrm{min}$. ILSS was calculated using equation. (2), where Pm refers to the applied load, b denotes specimen thickness, and $\mathrm{h}$ represents specimen width.

$$
\text { ILSS }=0.75 \times \frac{P_{m}}{b \times h}
$$

The impact strength test was conducted in accordance with ASTM D256. A $2.75 \mathrm{~J}$ hammer was used to hit the specimen; the hammer length was $326.8 \mathrm{~mm}$, initial hammer support angle was $150^{\circ}$, impact height was $610 \mathrm{~mm}$, and impact speed was $3.46 \mathrm{~m} / \mathrm{s}$.

A CTE measurement device was used to examine the thermal stability of the fabricated hybrid NCF composites. The thermal expansion test was conducted in accordance with ASTM E288; the measurement temperature range was $25-90{ }^{\circ} \mathrm{C}$ under a helium gas atmosphere of 300 $\mathrm{ml} / \mathrm{min}$, and the force of the push rod was $0.2 \mathrm{~N}$.

Arithmetic averages of ten, seven, five, and two measurements were taken to determine the tensile strength (impact strength), ILSS, contact angle, and CTE of the NCF composites, respectively.

Table 3. London dispersive $\left(\gamma_{L}^{L}\right)$ and specific $\left(\gamma_{L}^{S P}\right)$ components of surface free energy $\left(\gamma_{L}\right)$ in wetti ng liquids, measured at $20^{\circ} \mathrm{C}$.

$$
\gamma_{L}^{L} / \mathrm{mJm}^{-2} \quad \gamma_{L}^{S P} / \mathrm{mJm}^{-2} \quad \gamma_{L} / \mathrm{mJm}^{-2}
$$

$\begin{array}{llll}\text { Water } & 51 & 21.8 & 72.8\end{array}$

$\begin{array}{llll}\text { Diiodomethane } & 0.38 & 50.42 & 50.8\end{array}$

\section{Results and discussion}

\subsection{FE-SEM analysis}

Figure 2 shows FE-SEM images of the microstructures of the specimen fracture surfaces, which were observed to evaluate the morphological changes of the hybrid NCF composites added with $\mathrm{SiO}_{2}$ nanoparticles and with APTMS-modified $\mathrm{SiO}_{2}$ nanoparticles.

Figure 2 (a) and (b) show images of the fracture surface of the hybrid NCF composite specimens added with $0.6 \mathrm{wt} \% \mathrm{SiO}_{2}$ nanoparticles and taken at 3,000 and 100,000 magnification. Fig. 2 (c) and (d) show images taken at 3,000 and 100,000 magnification for the fracture surface of the hybrid NCF composite specimens added with surface-modified $\mathrm{SiO}_{2}$ nanoparticles. 
In Fig. 2 (b), agglomerates of $\mathrm{SiO}_{2}$ nanoparticles appear in several places in the resin, whereas in (d), the $\mathrm{SiO}_{2}$ nanoparticles are distributed relatively evenly owing to the modification with the silane coupling agent. As mentioned in the Introduction, the modified $\mathrm{SiO}_{2}$ nanoparticles in the resin appear less agglomerated because the functional groups of the silane coupling agent restrict the hydrogen bond formation between the particles. Regarding the failure mode, the elongated matrix in (a) was almost destroyed. By contrast, the matrix in (c), which contained modified $\mathrm{SiO}_{2}$ nanoparticles, bonded well with the NCFs, despite fracture.
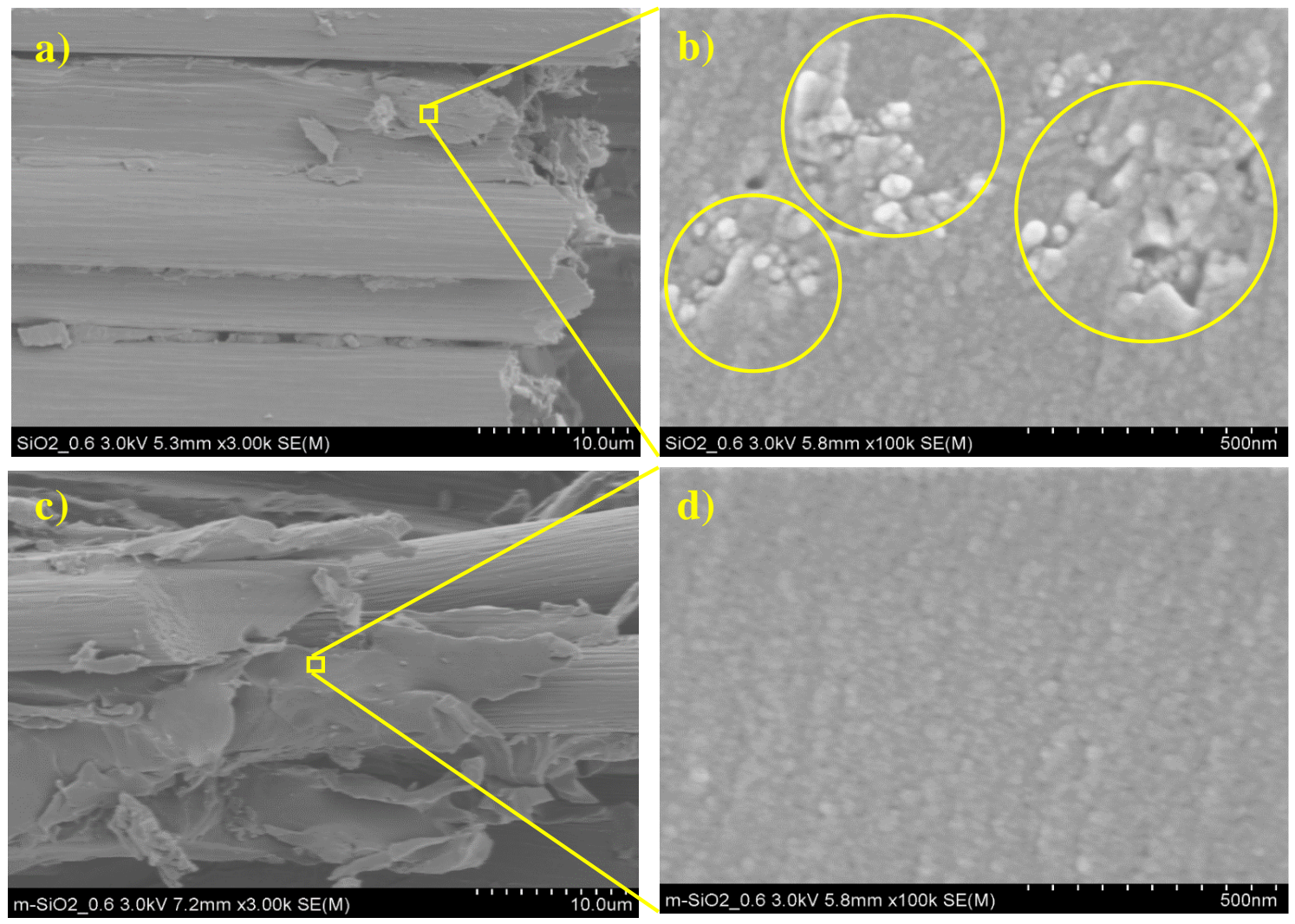

Figure 2. FE-SEM images of the fracture surface of the hybrid NCF composite specimens added with $0.6 \mathrm{wt} \% \mathrm{SiO}_{2}$ nanoparticles and $0.6 \mathrm{wt} \%$ APTMS-modified $\mathrm{SiO}_{2}$ nanoparticles.

\subsection{Surface free energy}

The effects of adding either unmodified or APTMS-modified $\mathrm{SiO}_{2}$ nanoparticles with the hybrid NCF composites on its polar, dispersive, and surface free energy were also examined, as shown in Table 4. When $\mathrm{SiO}_{2}$ nanoparticles were added to the NCFs, its polar increased greatly by the hydrophilic hydroxyl and silanol groups that existed on the silica surface. When the $\mathrm{SiO}_{2}$ nanoparticles modified by APTMS were added to the NCFs, its dispersive was greatly increased by the functional groups present in the APTMS. This result indicated that the silane coupling agent had a high surface energy and dispersive elements [37]. In particular, it was expected that when surface-modified $\mathrm{SiO}_{2}$ nanoparticles were added to $\mathrm{NCF}$, excellent interfacial adhesion would occur between the matrix resins and NCFs with high non-polar, and the dispersibility of $\mathrm{SiO}_{2}$ nanoparticles in the resins would be improved, resulting in increasing the mechanical strength of the composites. (See the sections 3.3 and 3.4). 
Table 4. Surface free energy of the NCFs studied.

\begin{tabular}{cccc}
\hline & $\boldsymbol{\gamma}_{S}^{L} / \mathbf{m J m}^{-2}$ & $\boldsymbol{\gamma}_{S}^{S P} / \mathbf{m J m}^{-2}$ & $\boldsymbol{\gamma}_{S} / \mathbf{m J m}^{-2}$ \\
\hline NCFs & 21.44 & 4.4 & 25.84 \\
NCFs \& Nano $\mathrm{SiO}_{2}$ & 22.35 & 13.25 & 35.6 \\
$\begin{array}{c}\text { NCFs \& APTMS- } \\
\text { modified nano } \mathrm{SiO}_{2}\end{array}$ & 28.67 & 13.65 & 42.31 \\
\hline
\end{tabular}

\subsection{ILSS}

The effects of adding either unmodified or APTMS-modified $\mathrm{SiO}_{2}$ nanoparticles with the hybrid NCF composites can be observed in the ILSS test results as shown in Fig. 3. The hybrid NCF composite specimens added with 0.3 and $0.6 \mathrm{wt} \% \mathrm{SiO}_{2}$ nanoparticles showed increase in the ILSS of approximately 5.4 and $8.2 \%$, respectively, relative to the ILSS of the epoxy composites reinforced with NCFs (baseline) specimens. In addition, the ILSS of the hybrid NCF composite specimens added with 0.3 and $0.6 \mathrm{wt} \%$ surface-modified $\mathrm{SiO}_{2}$ nanoparticles increased by approximately 18.4 and $26.6 \%$, respectively, relative to that of the baseline specimens.

The strength of an FRP is regulated by the properties of the fiber itself (type, length, and arrangement) and the interfacial bonding between the fiber and resin. As shown by the ILSS test results, $\mathrm{SiO}_{2}$ nanoparticles improved the weak physical bond between the fiber and the resin, which agrees with the results of previous studies. When the resin with surface-modified $\mathrm{SiO}_{2}$ nanoparticles dispersion are infused to the stacked NCFs and between the layers of NCFs, hydrogen and siloxane bonds are formed between the fiber and resin, as can be observed from the reaction mechanism in Fig. 1. Furthermore, it is assumed that the chemical bond formed by the condensation reaction further improves the interfacial bonding strength between the NCFs and epoxy resin after curing [38-40]. Consequently, the hybrid NCF composite specimens displayed a significantly higher ILSS as compared to the other two specimens. This finding is similar to that of Zhang et al. [41]. 


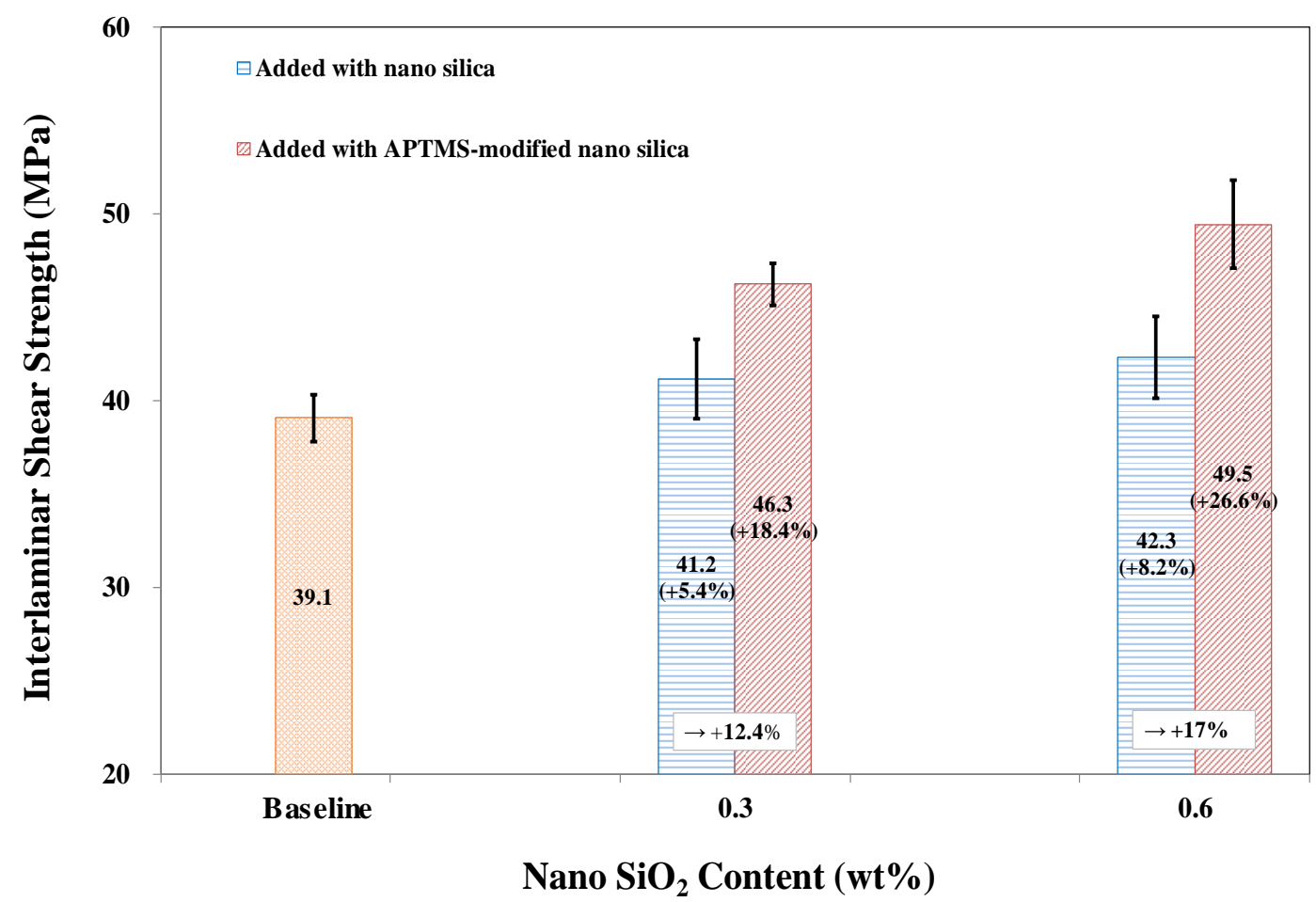

Figure 3. ILSS of the hybrid NCF composite specimens added with several contents of $\mathrm{SiO}_{2}$ nanoparticles and APTMS-modified $\mathrm{SiO}_{2}$ nanoparticles.

\subsection{Tensile strength}

The effects of adding either unmodified or APTMS-modified $\mathrm{SiO}_{2}$ nanoparticles with the hybrid NCF composites on its tensile strength were also examined, as shown in Fig. 4. The tensile strength of the hybrid NCF composite specimens added with 0.3 and $0.6 \mathrm{wt} \% \mathrm{SiO}_{2}$ nanoparticles increased by approximately 7.2 and $13.7 \%$, respectively, relative to that of the baseline specimens. Meanwhile, the hybrid NCF composite specimens added with 0.3 and $0.6 \mathrm{wt} \%$ surface-modified $\mathrm{SiO}_{2}$ nanoparticles showed tensile strength increase of approximately 18.7 and $26.7 \%$, respectively, compared to that of the baseline specimens.

As shown in Fig. 4, as the $\mathrm{SiO}_{2}$ content increased, the mechanical properties of the hybrid NCF composite specimens improved. This finding are considered the result of the epoxy resin and $\mathrm{SiO}_{2}$ nanoparticle mixture impregnating the NCFs, in which the $\mathrm{SiO}_{2}$ nanoparticles with high strength and rigidity were dispersed in the epoxy resin. At this time, $\mathrm{SiO}_{2}$ nanoparticles may effectively reduce the stress concentration and dissipate more deformation energy in the NCF composites.

The even distribution of $\mathrm{SiO}_{2}$ nanoparticles and their strong interfacial bonding with the matrix are the most significant factors that improve the mechanical strength of the resulting composite. The surface-modified $\mathrm{SiO}_{2}$ nanoparticles showed better dispersibility and interfacial bonding in the NCF composites.

Thus, the corresponding hybrid NCF composite specimens distributed the applied tensile stress more effectively and provided higher tensile strength compared to that of the other composites. 


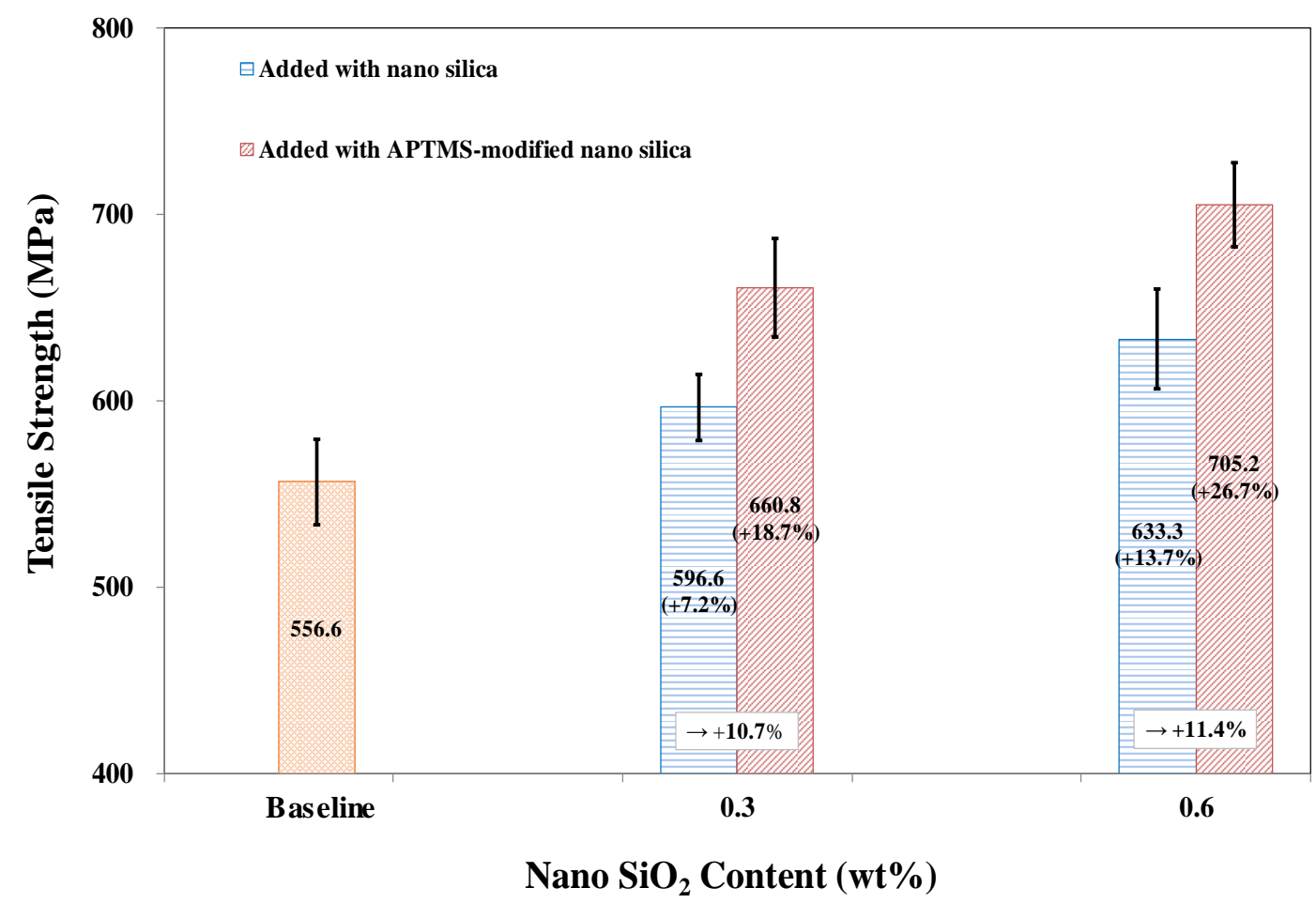

Figure 4. Tensile strength of the hybrid NCF composite specimens added with several contents of $\mathrm{SiO}_{2}$ nanoparticles and APTMS-modified $\mathrm{SiO}_{2}$ nanoparticles.

\subsection{Impact strength}

To examine the effects of the $\mathrm{SiO}_{2}$ nanoparticles on the impact strength, Izod impact strength tests were performed on the NCF composites; the results of specimens are shown in Fig. 5. When an impact is applied to the baseline specimen, fractures form in parallel from the tip of the Vnotch to the end of failure. In addition, crack growth is accelerated by the propagation of the matrix crack along the NCFs and matrix interface, and failure occurs near the location of stress concentration.

The impact strength of the hybrid NCF composite specimens added with 0.3 and 0.6 wt $\%$ $\mathrm{SiO}_{2}$ nanoparticles increased by approximately 8.8 and $15.4 \%$, respectively, compared with that of the baseline specimens. In contrast, the hybrid NCF composite specimens added with 0.3 and $0.6 \mathrm{wt} \%$ surface-modified $\mathrm{SiO}_{2}$ nanoparticles showed the increase of approximately 17.8 and 24.7 $\%$, respectively, relative to that of the baseline specimens, thus demonstrating the beneficial effect of silane modification.

Figure 5 shows that the $\mathrm{SiO}_{2}$ nanoparticles either prevent the crack growth caused by the impact or change the direction of the crack propagation and absorb the impact energy. Landowski et al. [42] reported that mixing $\mathrm{SiO}_{2}$ nanoparticles into the CFRP reduced both the impact damage range and the crack length. In particular, the impact strength is affected by the interfacial bonding between the fiber and the resin. Thus, mixing the modified and unmodified $\mathrm{SiO}_{2}$ nanoparticles with the hybrid NCF composite specimens improved their interfacial bonding strength and hence increased the impact strength. 


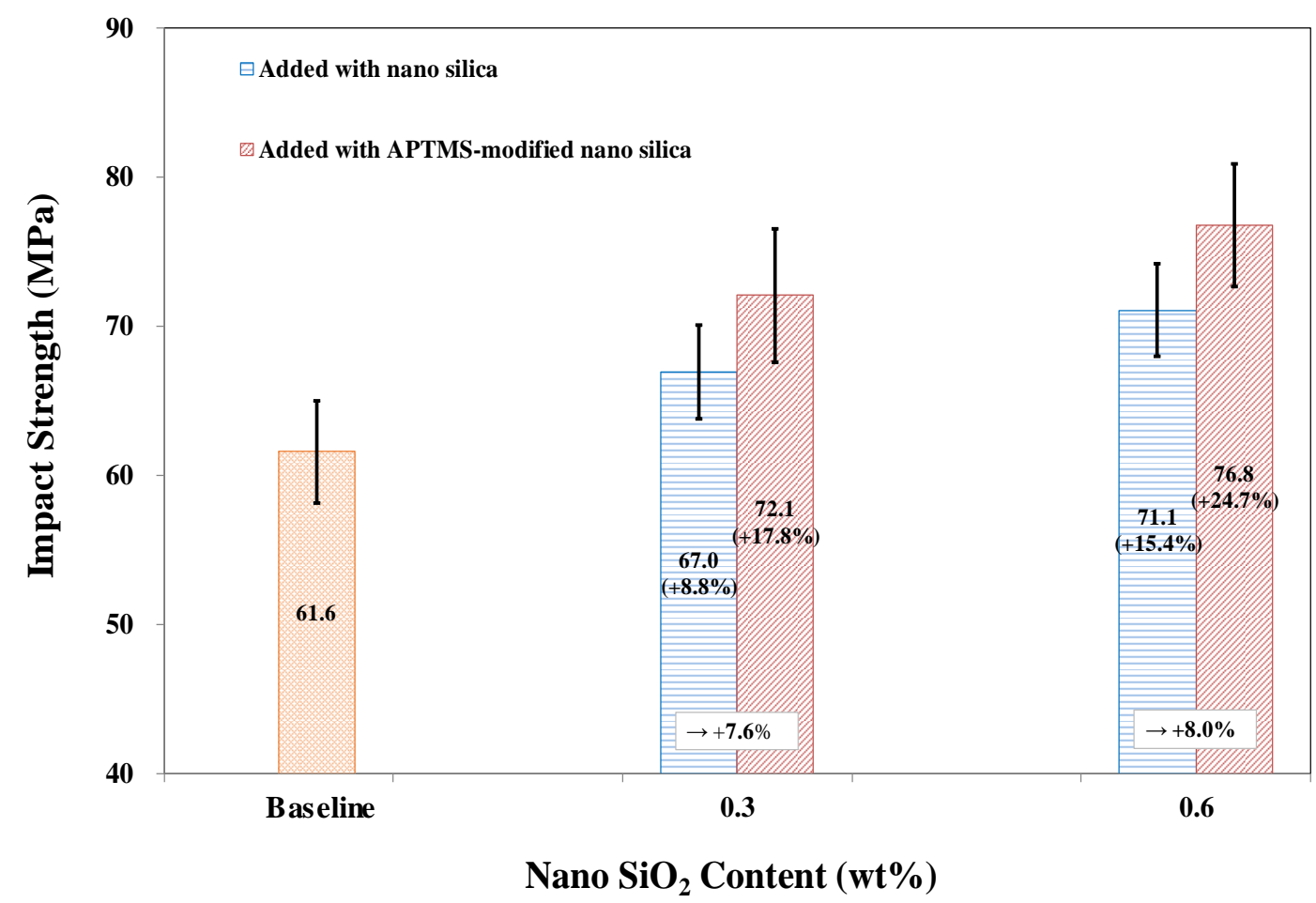

Figure 5. Impact strength of the hybrid NCF composite specimens added with several contents of $\mathrm{SiO}_{2}$ nanoparticles and APTMS-modified $\mathrm{SiO}_{2}$ nanoparticles.

\subsection{Coefficient of thermal expansion}

The effects of adding either unmodified or APTMS-modified $\mathrm{SiO}_{2}$ nanoparticles on the CTE at $70{ }^{\circ} \mathrm{C}$ were examined by comparison with the CTE of the baseline specimens; the results are shown in Fig. 6. The CTE of the hybrid NCF composite specimens added with 0.3 and $0.6 \mathrm{wt} \%$ $\mathrm{SiO}_{2}$ nanoparticles reduced by approximately 10.9 and $15.3 \%$, respectively, compared with that of the baseline specimens. Further, the hybrid NCF composite specimens added with 0.3 and 0.6 $\mathrm{wt} \%$ showed reduction in the CTE of approximately 33.4 and $34.3 \%$, respectively, relative to that of the baseline specimens.

When an FRP is exposed to a high temperature for a long time, it can undergo deformations such as delamination and bending owing to the thermal stress caused by the difference in the CTEs of the fiber and the resin. Fig. 6 reveals that when the content of the $\mathrm{SiO}_{2}$ nanoparticles increased, the CTE of the composite gradually decreased relative to that of the baseline specimens. This trend is the result of the increasing volume fraction of the additive $\left(\mathrm{SiO}_{2}\right)$ in the composite. The $\mathrm{SiO}_{2}$ nanoparticles have a very low CTE, which is approximately $1 / 70$ th of that of epoxy resin $[43,44]$. Meanwhile, when surface-modified $\mathrm{SiO}_{2}$ nanoparticles were added into the resin, the CTE decreased more sharply. This is because the functional groups generated by the $\mathrm{SiO}_{2}$ modification with the silane coupling agent limited the mobility of the polymer chains, thus reducing the thermal strain of the composite specimens. The functional groups generated by surface modification of $\mathrm{SiO}_{2}$ nanoparticles could effectively reduce the CTE of the composite by improving the interfacial interactions and suppressing the free volume increase in the composite [45]. 


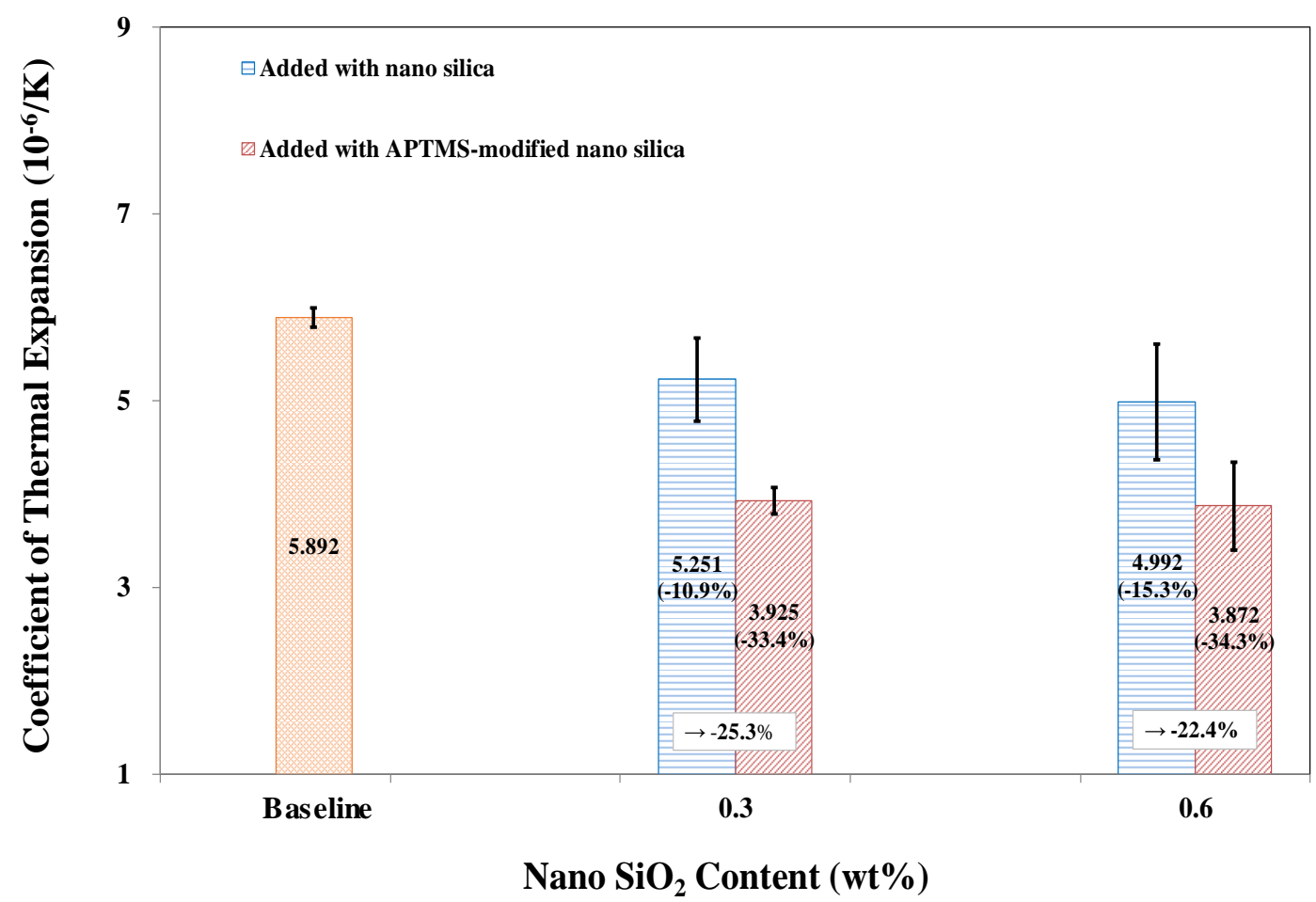

Figure 6. CTE of the hybrid NCF composite specimens added with several contents of $\mathrm{SiO}_{2}$ nanoparticles and APTMS-modified $\mathrm{SiO}_{2}$ nanoparticles.

\section{Conclusions}

The analysis of the mechanical and thermal properties of the hybrid NCF composites demonstrated that the performance of such composites could be significantly improved by adding either unmodified or APTMS-modified $\mathrm{SiO}_{2}$ nanoparticles in the composite matrix. The conclusions of this study are as follows:

1. Increasing the content of $\mathrm{SiO}_{2}$ nanoparticles improved the mechanical properties of the hybrid NCF composites, which is considered the result of impregnating the NCFs with a mixture of an epoxy resin and $\mathrm{SiO}_{2}$ nanoparticles, where the nanoparticles have higher strength and rigidity than those of the epoxy resin. This finding suggests that the $\mathrm{SiO}_{2}$ nanoparticles increase the interfacial bonding strength, effectively distribute the stress applied to the specimen, and absorb the impact energy.

2. An examination of the effects of modifying the $\mathrm{SiO}_{2}$ nanoparticles with a silane coupling agent revealed that the formation of stable bonds among the $\mathrm{NCF} s, \mathrm{SiO}_{2}$ nanoparticles, and resin further improved the mechanical properties of the hybrid NCF composites. This improvement is the result of higher interfacial bonding strength between the organic and inorganic materials owing to the surface modification of the $\mathrm{SiO}_{2}$ nanoparticles, which promotes favorable additive and matrix interactions.

3. The mechanical properties improved when the NCF composites were added with either $\mathrm{SiO}_{2}$ nanoparticles or surface-modified $\mathrm{SiO}_{2}$ nanoparticles. The hybrid composites added with 0.6 $w t \%$ modified $\mathrm{SiO}_{2}$ nanoparticles showed higher increase in the ILSS, tensile strength, and impact 
strength of approximately $26.6 \%, 26.7 \%$, and $24.7 \%$, respectively, relative to those of the NCF composites.

4. The CTE decreased when the NCF composites were added with $\mathrm{SiO}_{2}$ nanoparticles or surface-modified $\mathrm{SiO}_{2}$ nanoparticles. This was due to the $\mathrm{SiO}_{2}$ having a significantly smaller CTE than the resin and the functional groups on the APTMS of the modified $\mathrm{SiO}_{2}$ nanoparticles restricting the mobility of the surrounding polymer chains. Thus, when the $\mathrm{SiO}_{2}$ nanoparticle content increased, it suppressed the free volume increase in the NCF composites, which in turn reduced thermal strain and increased thermal stability of the composite.

Acknowledgement: This research was supported by basic Science Research Program through the National Research Foundation of Korea (NRF) funded by the Ministry of Education, Jeonju University (Grant No. 2016R1A6A1A03012069) and partly supported by the Korea Institute of Carbon Convergence Technology (KCTECH).

\section{References}

1. Kobayashi, S.; Plotkin, S.; Ribeiro, S.K. Energy efficiency technologies for road vehicles, Energy Efficiency 2009, 2, 125-137.

2. Mattson, D.; Joffe, R.; Varna, R.J. Damage in NCF composites under tension: Effect of layer stacking sequence. Eng. Fract. Mech. 2008, 75, 2662-2682.

3. Wang, Y.J. Mechanical properties of stitched multiaxial fabric reinforce composites from mannual layup process. Appl. Compos. Mater. 2002, 9, 81-97.

4. Mahadik, Y.; Hallett, S. Effect of fabric compaction and yarn waviness on 3D woven composite compressive properties. Compos. Part A Appl. Sci. Manuf. 2011, 42(11), 1592-1600.

5. Shipsha, A.; Hallstrom, S.; Burman, M. Effect of stacking sequence and bundle waviness in quasiisotropic NCF composites subjected to compression., Compos. Part B Eng. 2019, 178, 107423.

6. Mattsson, D.; Joffe, R.; Varna, J. Methodology for characterization of internal structure parameters governing performance in NCF composites. Compos. Part B Eng. 2007, 38, 44-57.

7. Shipsha, A.; Burman, M. Failure mechanisms in NCF composite bolted joints: Experiments and FE model. Compos. Part B Eng. 2020, 192, 107950.

8. Kong, H.; Mouritz, A.P.; Paton, R. Tensile extension properties and deformation mechanisms of multiaxial non-crimp fabircs. Composite Structures 2004, 66, 249-259.

9. Sasikumar, A.; Trias, D.; Costa, J.; Blanco, N.; Orr, J.; Linde, P. Impact and compression after impact response in thin laminates of spread-tow woven and non-crimp fabrics. Composite Structures 2019, 215, 432-445.

10. Edgren, F.; Asp, L.E.; Joffe, R. Failure of NCF composites subjected to combined compression and shear loading. Compos. Sci. Technol. 2006, 66, 2865-2877.

11. Gao, B.; Zhang, R.; He, M.; Sun, L.; Wang, C.; Liu, L. Effect of a multiscale reinforcement by carbon fiber surface treatment with graphene oxide/carbon nanotubes on the mechanical properties of reinforced carbon/carbon composites. Compos. Part A Appl. Sci. Manuf. 2016, 90, 433-440.

12. Zhang, X.; Fan, X.; Yan, C.; Li, H.; Zhu, Y.; Li, X. Interfacial microstructure and properties of carbon fiber composites modified with graphene oxide. ACS Appl. Mater. Interfaces 2012, 4, 1543-1552.

13. Chiang, C.L.; Chou, H.Y.; Shen, M.Y. Effect of environmental aging on mechanical properties of graphene nanoplatelet/nanocarbon aerogel hybrid-reinforced epoxy/carbon fiber composite laminates. Compos. Part A Appl. Sci. Manuf. 2020, 130, 105718.

14. Nguyen, T.C.; Bai, Y.; Al-Mahaidi, R.; Zhao, X.L. Time-dependent behaviour of steel/CFRP double strap joints subjected to combined thermal and mechanical loading. Compos. Struct. 2012, 94(5), 18261833. 
15. Gholami, M.; Sam, A.R.M.; Yatim, J.M.; Tahir, M.M. A review on steel/CFRP strengthening systems focusing environmental performance. Constr. Build. Mater. 2013, 47, 301-310.

16. Alessi, S.; Pitarresi, G.; Spadaro, G. Effect of hydrothermal ageing on the thermal and delamination fracture behaviour of CFRP composites. Compos. Part B Eng. 2014, 67, 145-153.

17. Wang, S.; Chen, Z.H.; Ma, W.J. Influence of heat treatment on physical-chemical properties of PANbased carbon fiber. Ceram. Int. 2006, 32, 291-295.

18. Zhang, R.L.; Huang, Y.D.; Li, N.; Liu, L.; Su, D. Effect of the concentration of the sizing agent on the carbon fibers surface and interface properties of its composites. J. Appl. Polym. Sci. 2012, 125(1), 425432.

19. Jiang, Q.; Li, R.; Sun, J.; Wang, C.; Peng, S.; Ji, F.; Yao, L.; Qiu, Y. Influence of ethanol pretreatment on effectiveness of atmospheric pressure plasma treatment of polyethylene fibers. Surf. Coat. Technol. 2009, 203(12), 1604-1608.

20. Lee, C.Y.; Bae, J.H.; Kim, T.Y.; Chang, S.H.; Kim, S.Y. Using silane-functionalized graphene oxides for enhancing the interfacial bonding strength of carbon/epoxy composites. Compos. Part A Appl. Sci. Manuf. 2015, 75, 11-17.

21. Rafiee, M.; Nitzsche, F.; Laliberte, J.; Hind, S.; Robitaille, F.; Labrosse, M.R. Thermal properties of doubly reinforced fiberglass/epoxy composites with graphene nanoplatelets, graphene oxide and reduced-graphene oxide. Compos. Part B Eng. 2019, 164, 1-9.

22. Khan, N.I.; Halder, S.; Das, S.; Wang, J. Exfoliation level of aggregated graphitic nanoplatelets by oxidation followed by silanization on controlling mechanical and nanomechanical performance of hybrid CFRP composites. Compos. Part B Eng. 2019, 173, 106855.

23. Zeng, X.; Yu, S.; Sun, R.; Xu, J.B. Mechanical reinforcement while remaining electrical insulation of glass fibre/polymer composites using core-shell $\mathrm{CNT} @ \mathrm{SiO}_{2}$ hybrids as fillers. Compos. Part A Appl. Sci. Manuf. 2015, 73, 260-268.

24. Rong, Z.; Sun, W.; Xiao, H.; Jiang, G. Effects of nano-SiO 2 particles on the mechanical and microstructural properties of ultra-high performance cementitious composites. Cem. Concr. Comp. 2015, 56, 25-31.

25. Jang, J.S.; Varischetti, J.; Lee, G.W.; Suhr, J.h. Experimental and analytical investigation of mechanical damping and CTE of both $\mathrm{SiO}_{2}$ particle and carbon nanofiber reinforced hybrid epoxy composites. Compos. Part A Appl. Sci. Manuf. 2011, 42, 98-103.

26. Oh, Y.; Kang, J.S.; Kang, C.S.; Kwon, K.C.; Lee, G.W. Investigation of mechanical, thermal and electrical properties of hybrid composites reinforced with multi-walled carbon nanotubes and fused silica particles. Carbon Lett. 2020, 30, 353-365.

27. Meier, J.G.; Fritzsche, J.; Guy, L.; Bomal, Y.; Klüppel, M. Relaxation dynamics of hydration water at activated silica interfaces in high-performance elastomer composites. Macromolecules 2009, 42(6), 2127-2134.

28. García, N.; Benito, E.; Guzmán, J.; Tiemblo, P. Use of p-toluenesulfonic acid for the controlled grafting of alkoxysilanes onto silanol containing surfaces: preparation of tunable hydrophilic, hydrophobic, and super-hydrophobic silica. J. Am. Chem. Soc. 2007, 129(16), 5052-5060.

29. Capel-Sanchez, M.C.; Barrio, L.; Campos-Martin, J.M.; Fierro, J.L.G. Silylation and surface properties of chemically grafted hydrophobic silica. J. Colloid Interface Sci. 2004, 277, 146-153.

30. Kulkarni, S.A.; Ogale, S.B.; Vijayamohanan, K.P. Tuning the hydrophobic properties of silica particles by surface silanization using mixed self-assembled monolayers. J. Colloid Interface Sci. 2008, 318(2), 372-379.

31. Kristensen, E.M.E.; Nederberg, F.; Rensmo, H.; Bowden, T.; Hilborn, J.; Siegbahn, H. Photoelectron spectroscopy studies of the functionalization of a silicon surface with a phosphorylcholine-terminated polymer grafted onto (3-aminopropyl)trimethoxysilane. Langmuir, 2006, 22(23), 9651-9657.

32. Oh, C.; Lee, J.H.; Lee, Y.G.; Lee, Y.H.; Kim, J.W.; Kang, H.H.; Oh, S.G. New approach to the immobilization of glucose oxidase on non-porous silica microspheres functionalized by (3aminopropyl)trimethoxysilane (APTMS). Colloid. Surface. B. 2006, 53(2), 225-232. 
33. Wei, B.; Song, S.; Cao, H. Strengthening of basalt fibers with nano-SiO2-epoxy composite coating. Mater. Des. 2011, 32, 4180-4186.

34. Yang, Y.; Lu, C.X.; Su, X.L.; Wu, G.P.; Wang, X.K. Effect of nano-SiO 2 modified emulsion sizing on the interfacial adhesion of carbon fibers reinforced composites. Mater. Lett. 2007, 61, 3601-3604.

35. Owens D. K.; Wendt R. C. Estimation of the Surface Free Energy of Polymers. J. Appl. Polym. Sci. 1969, 13, 1741-1747.

36. Kaelble D. H.; Uy K. C. A Reinterpretation of Organic Liquid-Polytetrafluoroethylene Surface Interactions. J. Adhesion, 1970, 2, 50-60.

37. Park, S.J.; Kim, B.J.; Seo, D.I.; Rhee, K.Y.; Lyu, Y.Y. Effects of a silane treatment on the mechanical interfacial properties of montmorillonite/epoxy nanocomposites, Mater. Sci. Eng. A. 2009, 526, 74-78.

38. Yoshida, W.; Castro, R.P.; Jou, J.D.; Cohen, Y. Multilayer alkoxysilane silylation of oxide surfaces. Langmuir, 2001, 17, 5882-5888.

39. Vilmin, F.; Bottero, I.; Travert, A.; Malicki, N.; Gaboriaud, F.; Trivella, A.; Thibault-Starzyk, F. Reactivity of bis[3-(triethoxysilyl)propyl] tetrasulfide (TESPT) silane coupling agent over hydrated silica: Operando IR spectroscopy and chemometrics study. J. Phys. Chem. C. 2014, 118, 4056-4071.

40. Howarter, J.A.; Youngblood, J.P. Optimization of silica silanization by 3aminopropyltriethoxysilane. Langmuir, 2016, 22(26), 11142-11147.

41. Zhang, T.; Xu, Y.; Li, H.; Zhang, B. Interfacial adhesion between carbon fibers and nylon 6: Effect of fiber surface chemistry and grafting of nano-SiO ${ }_{2}$ Compos. Part A Appl. Sci. Manuf. 2019, 121, 157168.

42. Landowski, M.; Strugała, G.; Budzik, M.; Imielinska, K. Impact damage in $\mathrm{SiO}_{2}$ nanoparticle enhanced epoxy carbon fibre composites. Compos. Part B Eng. 2017, 113, 91-99.

43. Jang, J.S.; Kim, H.I.; Gibson, R.F.; Suhr, J.H. Effective in situ material properties of micron-sized $\mathrm{SiO}_{2}$ particles in $\mathrm{SiO}_{2}$ particulate polymer composites. Mater. Des. 2013, 51, 219-224.

44. Vetterli, M.; Tavangar, R.; Weber, L.; Kelly, A. Influence of the elastic properties of the phases on the coefficient of thermal expansion of a metal matrix composite. Scr. Mater. 2011, 64, 153-156.

45. Li, G.; He, Y.; Zhu, P.; Zhao, T.; Sun, R.; Lu, D.; Wong, C.P. Tailored surface chemistry of $\mathrm{SiO}_{2}$ particles with improved rheological, thermal-mechanical and adhesive properties of epoxy based composites for underfill applications. Polymer 2018, 156, 111-120. 